\title{
Land-Air Interactions over Urban-Rural Transects Using Satellite Observations: Analysis over Delhi, India from 1991-2016
}

\author{
Madhavi Jain ${ }^{1}$ (D), A. P. Dimri ${ }^{1, *}$ and Dev Niyogi ${ }^{2}$ \\ 1 School of Environmental Sciences, Jawaharlal Nehru University, New Delhi 110067, India; \\ madhavi.jain@ymail.com \\ 2 Department of Agronomy, and Department of Earth, Atmospheric, and Planetary Sciences, \\ Purdue University, West Lafayette, IN 47907, USA; dniyogi@purdue.edu \\ * Correspondence: apdimri@hotmail.com
}

Received: 28 September 2017; Accepted: 7 December 2017; Published: 20 December 2017

\begin{abstract}
Over the past four decades Delhi, India, has witnessed rapid urbanization and change in land use land cover (LULC) pattern, with most of the cultivable areas and wasteland being converted into built-up areas. Presently around $40 \%$ land is under built-up area, a drastic rise of $30 \%$ from 1977. The effect of changing LULC, at a local scale, on various variables-land surface temperature (LST), normalized difference vegetation index (NDVI), emissivity, albedo, evaporation, Bowen ratio, and planetary boundary layer (PBL) height, from 1991-2016, is investigated. To assess the spatio-temporal dynamics of land-air interactions, we select two different $100 \mathrm{~km}$ transects covering the NE-SW and NW-SE expanse of Delhi and its adjoining areas. High NDVI and emissivity is found for regions with green cover and drastic reduction is noted in built-up area clusters. In both of the transects, land surface variations manifest itself in patterns of LST variation. Parametric and non-parametric correlations are able to statistically establish the land-air interactions in the city. NDVI, an indirect indicator for LULC classes, significantly helps in understanding the modifications in LST and ultimately air temperature. Significant, strong positive relationships exist between skin temperature and evaporation, skin temperature and PBL height, and PBL height and evaporation, providing insights into the meteorological changes that are associated with urbanization.
\end{abstract}

Keywords: LULC; LST; transect; land-air interactions; remote sensing; correlation

\section{Introduction}

One of the most notable ways in which humans alter the environment is through the process of urbanization. Land previously occupied by vegetation, forests, or even barren soils is converted to built-up areas for residential, commercial and other purposes. Such is the state of affairs, that while only $3 \%$ of the earth's surface area is urban it supports more than $50 \%$ of the world's population [1]. The rapid pace of urbanization is likely to continue globally, but more so in the developing countries [2]. A city is a functionally complex and a highly dynamic ecosystem [3] composed of high and low-rise buildings differing in their compactness and interspersed with natural elements e.g., trees, waterbodies and grasslands [4]. Cities are livelihood and business centers catering to tens of millions of people. Urban ecosystems as a result are vulnerable to climate change impacts [5-7] and are in turn also capable of modifying its climate [8-12].

How land-atmosphere interactions at regional scales are coupled in the complex urban ecosystem along with their feedback systems is still not very well understood [13]. At a local scale, land and the overlying atmospheric system mutually interact with one another through various exchanges of energy and moisture [14]. Land surface projects its microclimatic effects to its atmospheric vicinity, 
which impacts the environment both laterally and in the vertical direction [15]. The extent over which the urban effects can impact the atmosphere is dependent on the magnitude of each variable along with the atmospheric conditions of stability. Over time in cities, particularly due to rampant urbanization, changes in land surface- both in the horizontal as well as in the vertical direction are expected.

The land use land cover (LULC) changes are directly responsible for modifications in the surface radiative fluxes [16]. The LULC changes can induce changes in the energy and water balance, and as a consequence can alter the local and regional climates [17]. Since intrinsic properties of urban materials, such as thermal conductivity, emissivity, specific heat capacity, surface roughness, albedo, and permeability [18-22] differ from elements of the natural environment they propagate as changes in the urban ecosystems [23]. A prominent effect of urbanization is therefore expected on net radiation, Bowen ratio (partitioning of the sensible and latent heat flux), soil moisture, and surface runoff $[17,24]$. The energy partitioning depends mainly on the amount of moisture that is available for evapotranspiration from the soil surface and sub-surface layers, and also from vegetation such as crops, forests, and grasslands [25]. Another noteworthy aspect is the evaporation component in cities provided by availability of around the year urban piped water supply. This continuous water supply apart from natural sources is required for the city functioning purposes, such as urban irrigation and intrinsic functioning [9]. The water used cities, in most cases, does not percolate at all into the soil owing to the presence of concretized impervious surfaces, and therefore becomes readily available for evaporation. In addition to evaporation, Bowen ratio by definition is linked to the latent and surface heat flux (thus indirectly linked to surface temperature), the amount of vegetation and dry air entrainment in the planetary boundary layer (PBL) [25]. Vegetation via transpiration is effective in moisture transfer to the overlying atmosphere [26]. Higher vegetation greenness that is typically found in dense forests is associated with high density of leaves, and therefore greater photosynthetically active radiation absorption [27]. Furthermore dense canopy provides shade, reducing sensible heat flux ultimately lowering temperature [28].

Urban structures on the other hand, cause heating of sunlit surfaces and cooling in shaded regions, as well as 'trap' radiation in the street canyons and cause changes in the structure of PBL [10]. Generally a decrease in latent heat flux due to reduced soil moisture and vegetation is noted in built-up areas. This reduction in latent heat flux in turn is compensated by increased fraction of sensible heat flux. Urban heat island, wherein temperature of the city core is higher than its rural surroundings is probably the most well documented modification by urban regions to the local climate $[4,8,29,30]$. In the past several decades, using climate records over the United States (U.S.), Foley et al. [17] attribute LULC changes especially from urbanization to the observed temperature rise. Focusing on anthropogenic input in the rise of $\mathrm{CO}_{2}$ emissions, they attribute $35 \%$ contribution from various land use practices. Similarly, other studies conclude various effects of urbanization and other LULC changes on the local, regional, and global climate. According to Stone et al. [6], highly sprawled cities of the U.S. report greater occurrences of extreme heat events than in compact cities. A $0.05{ }^{\circ} \mathrm{C}$ per decade rise in mean surface temperature and a decrease in the range of diurnal temperature in southeast China has been implicated to rapid urbanization [31]. Seneviratne et al. [32] demonstrate the role of land-air interactions specific to eastern and central Europe. They find through simulations that such coupling influences both the temperature variability in summer season and the water cycle on the whole. Other modifications in meteorological processes, such as precipitation extreme [33-35], thunderstorm [36], and lightning [37,38] events exhibit the potential of built-up areas in inducing changes in the atmosphere. Overall, it can be said that soil moisture-temperature-precipitation feedbacks are intimately connected with land-air interactions, and at a regional scale also have the potential to shift climatic zones [32].

There is a scarcity of studies focusing on the role played by local scale LULC changes in inducing regional modifications in the overlying atmosphere. Therefore, in the present study, we take this opportunity to study the land-air interactions over Delhi, a very rapidly urbanizing city, using multiyear satellite dataset. The city $\left(76.84^{\circ}-77.35^{\circ} \mathrm{E}, 28.41^{\circ}-28.88^{\circ} \mathrm{N}\right)$ lies in the Indo-Gangetic 
plains in northern India, has semi-arid climate characteristics and receives majority of rainfall from the Indian Summer Monsoon. Over the course of the past four decades, more than 30\% land area in Delhi, otherwise allotted to other land uses has been converted to built-up area. Thus, the gross percentage of built-up area in the city, in 2014, amounted to approximately 40\% [39].

Figure 1a-c shows the qualitative metadata representing LULC changes over the years inside the administrative boundary of Delhi. We seek to examine the spatio-temporal effects of changing LULC on various variables that are associated with the atmosphere for two representative transects over Delhi and its neighbouring areas. In the absence of ground observational data, we employ the use of remotely sensed data from Landsat satellite and ERA-Interim reanalysis dataset from the European Centre for Medium Range Weather Forecasts (ECMWF) [40] for the present study. Section 2 details the selection of transects along with materials and methods that are used in the study. Sections 3 and 4 presents the results and conclusions, respectively.

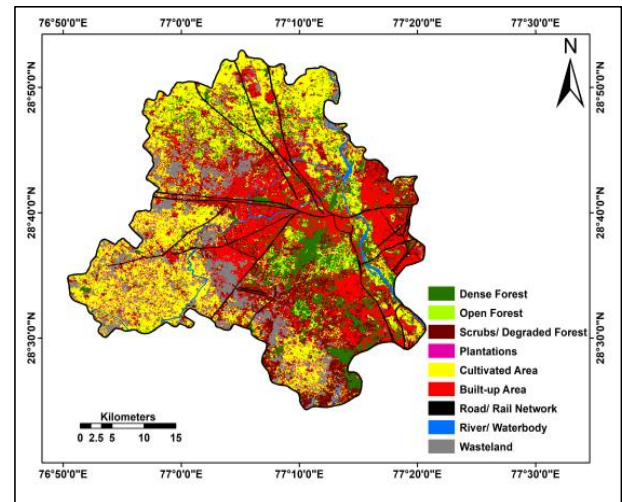

(a)

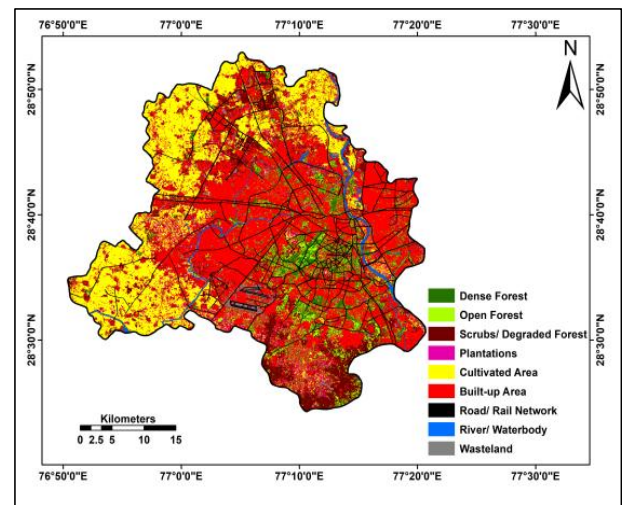

(c)

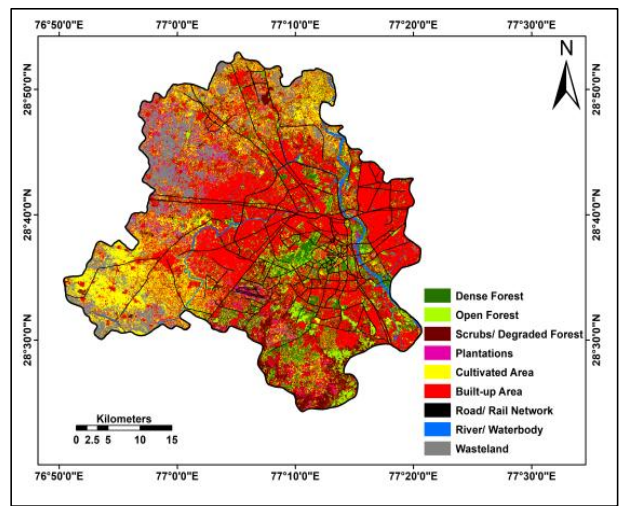

(b)

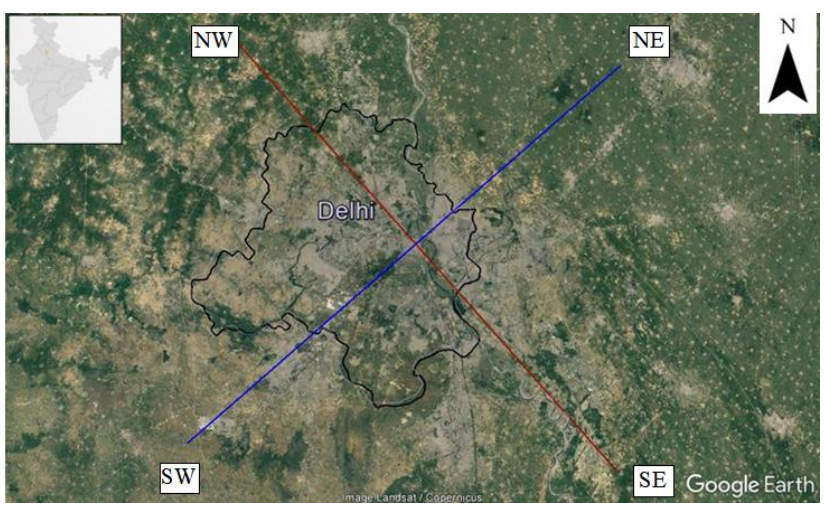

(d)

Figure 1. Land use land cover (LULC) maps of Delhi, India [39] for the years (a) 1993; (b) 2006; and (c) 2014; and (d) representative Google Earth map showing two $100 \mathrm{~km}$ transects in NE-SW (L1, blue line) and NW-SE (L2, red line) directions with central business district i.e., Old Delhi at the centre.

\section{Materials and Methods}

Three variables from Landsat dataset-land surface temperature (LST), normalized difference vegetation index (NDVI), and emissivity, as derived at $30 \mathrm{~m}$ spatial resolution and five variables from ERA-Interim dataset- skin temperature, albedo, evaporation, Bowen ratio, and PBL height, derived at $0.125^{\circ}$ spatial resolution are used in the study. ERA-Interim is a global atmospheric reanalysis gridded dataset available from 1979 (real time dataset from 1989 onwards) [40] at various horizontal resolutions ranging from $0.125^{\circ}$ to $3^{\circ}$ [41]. Meteorological variables and fluxes derived from $0.125^{\circ}$ resolution ERA-Interim dataset roughly matches the ground observations in a study performed by Zhou and Wang [42]. ERA-Interim uses the roughness length and drag coefficient to represent the effects of land 
use as well as dominant vegetation type in its forecast model [40]. Both these introductions alter drag taking place over land in a complex manner. Dee et al. [40] further elaborate that Tiled ECMWF Scheme for Surface Exchanges over Land (TESSEL) scheme in the model's land surface component (based on Global Land Cover Characterization (GLCC) dataset) is used to update various generated variables. When compared to other reanalysis products that are available over the Indian region, ERA-Interim dataset simulates the conditions in a better manner, and is therefore a widely acceptable dataset [43].

The study uses all available cloud free imageries (216 in total) from Landsat database and daily mean gridded data from ERA-Interim database, over the study region from 1991 to 2016. Flowchart provided in Figure 2, describes the methodology used in obtaining Landsat derived variables from the raw satellite data. Landsat data is available on the USGS Glovis portal, in the form of digital numbers (DN) for different wavelength bands. Thermal infrared $(10.4-12.5 \mu \mathrm{m})$ band is used to quantify brightness temperature, while red $(0.63-0.69 \mu \mathrm{m})$ and near infrared $(0.77-0.90 \mu \mathrm{m})$ bands are used for estimation of NDVI and emissivity. Data gaps present in imageries acquired from Landsat 7 SLC-off time period i.e., from 2003 to 2013 are corrected using filtering technique [44] prior to the calculation of Landsat derived variables. This pre-processing is done for all of the considered bands of Landsat 7 SLC-off imageries (56 in total).

For each image (216 in total), brightness temperature is estimated [44]. As the first step involved, $\mathrm{DN}$ is converted to spectral radiance values by spectral scaling method elaborated in the Landsat 7 Handbook [45]. The range of DN values is 0-255 for Landsat 5 and 7, and is 0-65536 for Landsat 8. Since Landsat level-1 products available from the USGS are not atmospherically corrected, the same is carried out following Sobrino et al. [46]. Planetary reflectance is estimated from the obtained spectral radiance values (in the earlier step; Figure 2) and is corrected for solar exo-atmospheric irradiance, sun elevation angle, and the earth-sun distance [45]. The values of sun elevation angle, earth-sun distance, etc. (gathered from metadata files) depend on the image acquisition date, and are therefore specific to each set of imagery. NDVI and emissivity for each set of imagery is estimated using the methodology described by Sobrino et al. [46]. Emissivity, a material property, is not directly proportional to NDVI, but is a function of wavelength. Although many various methods exist in literature to quantify emissivity, estimation in the present study is based on NDVI due to the reasoning that few LULC classes have seasonal behavior e.g., forests, agriculture, and waterbodies [46]. The modified NDVI thresholds method, as described by Sobrino et al. [46], is followed, wherein different empirical relationships exist between NDVI and emissivity for different threshold classes. Proportion of vegetation is quantified when NDVI ranges from 0.2 to 0.5 and used further in emissivity estimation. In the final step, LST is estimated by following the method detailed by Tran et al. [47].

The methodology described in Figure 2 is repeated for all 25 years of considered Landsat imageries (216 in total). Further detailed methodology is elaborated in Jain et al. [48]. ERA-Interim dataset provides all of the variables considered in the present study except for Bowen ratio in their database. Bowen ratio is calculated as a fraction of two other variables-surface sensible heat flux and surface latent heat flux [24].

Since there is no availability of Landsat thermal data prior to 1990, LULC data of three years-1993, 2006, and 2014, over Delhi is acquired from Jain et al. [39]. This 30m spatial resolution dataset comprises of nine categories of LULC, namely: (1) Dense Forest (2) Open Forest (3) Scrubs/ Degraded Forest (4) Plantations (5) Cultivable Area (6) Built-up Area (7) Road/ Rail Network (8) River/ Waterbody, and (9) Wasteland. The abovementioned LULC years-1993, 2006, and 2014 are used to represent the roughly decadal time periods 1991-1999 (hereafter as T1), 2000-2008 (hereafter as T2), and 2009-2016 (hereafter as T3) respectively, for all of the considered variables in the study. The assumption is valid due to the reason that LULC does not change notably on a monthly or a yearly scale. However, some LULC classes, such as forests and agriculture, show seasonality in state of vegetation. Thus, the three time periods are further divided into four seasons: December-January-February (DJF), March-April-May (MAM), June-July-August-September (JJAS), and October-November (ON). Seasons are defined on the basis of India Meteorological Department classification. LST is a variable with short autocorrelation length as it 
is highly dependent on absorbed radiation, as well as latent and sensible heat fluxes. Since the average temperature within a season remains fairly similar, the possible error due to LST autocorrelation is minimized. Further, to negate the decadal changes in the time series of the variables (which might be because of climatic conditions such as El-Nino), the study bifurcates the 25-year time series into T1, T2, and T3, as mentioned above.

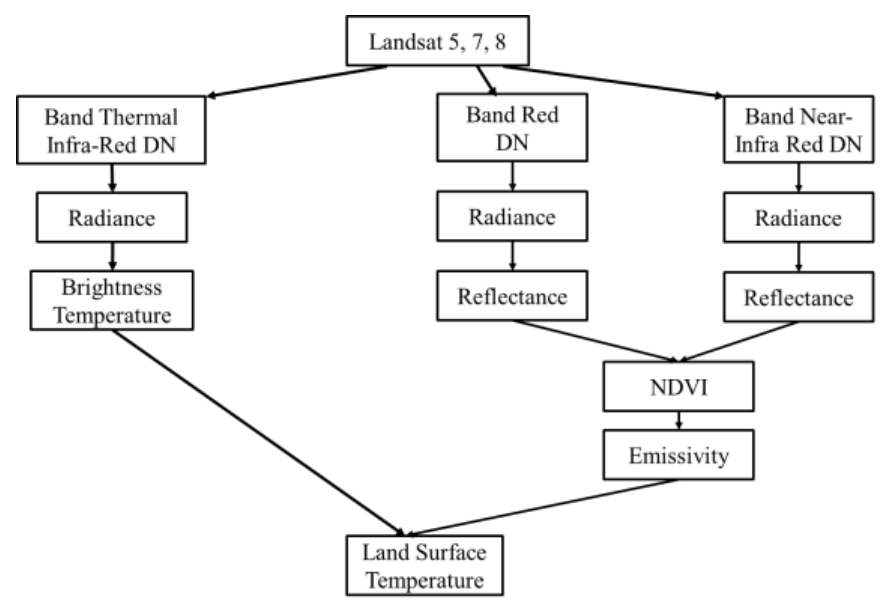

Figure 2. Flowchart of methodology used in obtaining Landsat derived variables—normalized difference vegetation index (NDVI), emissivity, and land surface temperature (LST) [39].

It is observed in all the three LULC years (Figure 1a-c) that spatial heterogeneity in terms of nine categories of LULC classes is highest in the NE-SW and NW-SE direction. Therefore two $100 \mathrm{~km}$ line transects are selected such that they pass through Old Delhi, the central business district of the city, in the middle (i.e., Old Delhi is at $50 \mathrm{~km}$ from both ends of the transect). We represent NE-SW transect as L1 and NW-SE transect as L2 from here on, and explore the land-air interactions on these transects. The selected transects are shown in Figure $1 \mathrm{~d}$.

A drawback of the present study is the unavailability of LULC data for the considered years 1993, 2006, and 2014 outside the administrative boundary of Delhi. In lieu of this, spatial LULC changes could not be plotted on the complete stretch of both transects. Also, as many micro-scale land use fluctuations are observed along both transects from the high spatial resolution $(30 \mathrm{~m})$ LULC maps that were acquired from Jain et al. [39], up-scaling of the original dataset to $250 \mathrm{~m}$ using the maximum likelihood classification approach is performed. This was necessary in order to make the local scale differences in LULC class distribution (along both transects and within the three time periods) in the graphs to be clearly visible to the reader. Similar up-scaling (from 30 to $250 \mathrm{~m}$ ) for the same reason is performed for all three Landsat derived variables viz. LST, NDVI, and emissivity on L1 and L2 transects, and are then plotted. In spite of the fact that ERA-Interim variables are too coarse, they were not down-scaled. The reason for this is that the data is already down-scaled to $0.125^{\circ}$ from $0.75^{\circ}$ by the data providers, and in order to reduce the uncertainty arising out of fine scale climate variability no further down-scaling is attempted. Down-scaled data from native $0.75^{\circ}$ does not include additional information and merely makes the finer resolution dataset $\left(0.125^{\circ}\right)$ look smoother, without increasing its accuracy. In terms of the ECMWF provided $0.125^{\circ}$ data, the interpolation might be introducing spurious spatial homogeneity in fine scale climatic features that are intended to be studied. In-spite of potentially large bias arising in this dataset (due to observation errors and model interpolation techniques) it is able to capture inter-seasonal and inter-decadal variability. In the absence of any other fine resolution meteorological dataset suited for the Indian region, ERA-Interim $0.125^{\circ}$ dataset is preferred. Prior to spatial profiling of ERA-Interim variables, all of the files are converted from netCDF to raster format. Spatial profiles of all Landsat and ERA-Interim variables in each time period are then superimposed on the representative LULC year data for both transects-L1 and L2, to look 
for possible land-air interactions. Seasonal changes have also been analyzed. Parametric (Pearson's r) and non-parametric (Spearman's $\varrho$ and Kendall's $\tau$ ) correlation tests are performed to study the relationships existing among the various studied variables.

\section{Results and Discussion}

\subsection{LULC Description along Transects}

High local scale spatio-temporal variations in LULC classes are noted along both transects. Moreover, on comparing between L1 and L2 transect, distinctly unique differences in LULC class patterns are seen, which is indicative of spatial heterogeneity existing within the city. About $30 \mathrm{~km}$ and $40 \mathrm{~km}$ stretch of L1 and L2 transect, respectively, lies inside the administrative boundary of Delhi (Figure 3). Each grey bar in Figures 3-5 represents one of the nine categories of LULC class (falling within the administrative boundary of Delhi) observed along the two transects at $250 \mathrm{~m}$ intervals. For each transect, drastic local scale LULC changes have occurred over time. Specifically focusing inside the city boundary for L1 transect, and moving from NE to SW direction, the following broad pattern of LULC change is observed- scrubs/degraded forest (41-43 km; T1) along with other forest classes and agriculture (45-50 km; T1) gets converted to built-up area in the following time periods. A major portion of dense forest $(53-60 \mathrm{~km})$ gets thinner over time. Conversion to predominantly built-up area from various classes is noted from T1 to T3 along the remaining stretch. Similarly moving from NW to SE direction along L2 transect, it is observed that most of the cultivated areas get converted to built-up areas over time (Figure 3). A brief description of LULC class patterns (as interpreted from Google Earth imagery, Figure 1d) of the remaining transect stretches falling beyond the city boundary is discussed. Major portion of the NE part $(\sim 0-40 \mathrm{~km})$ of $\mathrm{L} 1$ transect comprises of cultivable area that is interspaced with small built-up area patches (wasteland near Delhi boundary), while the SW portion $(\sim 70-100 \mathrm{~km})$ beyond the Delhi border is mainly the rocky terrain of the Aravalli range. When looking at the NW part ( 0-20 km) of L2 transect, the presence of primarily cultivated area is seen along with patches of wasteland, whereas, the SE part $(\sim 60-100 \mathrm{~km})$ of the transect is a mix of built-up area, open forest, and wasteland.

\subsection{Land-Air Interactions over the Transects}

Spatial profiling of different Landsat and ERA-Interim variables over two selected transects-L1 and L2, as described in Section 2, has been performed to evaluate the impact of changing land surface over them. Distribution of LULC regime in both transects is not homogenous within any time period. Sensible and latent heat fluxes play a crucial role in affecting LST, an important surface variable [21]. However, these fluxes are in turn affected by changes in LST as well. Any change in LST will produce modifications in the atmosphere as it is linked to air temperature through sensible heat flux [49]. A notable pattern in LST from Figure 3 is observed; it mirrors the LULC class patterns in space and associated changes in time. For the same time period, both L1 and L2 show markedly distinct LST patterns. The patterns that were observed in both transects are in general similar across all seasons, indicating that local land use factors do play a major role in altering LST. Higher local variations in LST are noted in L1 than in L2. It is a direct manifestation of the type of land surface in each transect and its inherent characteristics. We explain such manifestation through the surface related changes in NDVI. The index is defined as the difference of reflected radiances in the visible and near-infrared region of the electromagnetic spectrum that is normalized by their sum [50]. Since NDVI is used in many studies used to classify LULC classes [20,51,52], it can be used as a quantitative proxy measure of land surface related changes. NDVI is in turn related to emissivity through proportion of vegetation [46]. Moreover, as per Stefan-Boltzmann law, emissivity is related to the fourth power of temperature. Therefore, even small changes in emissivity produce large variations in LST and ultimately in air temperature. 
L1
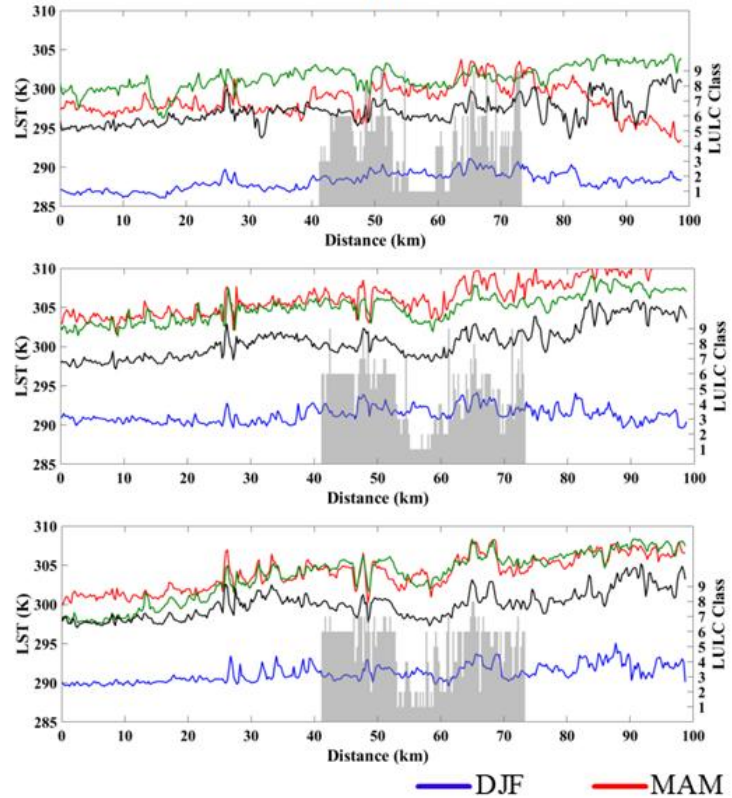

L2
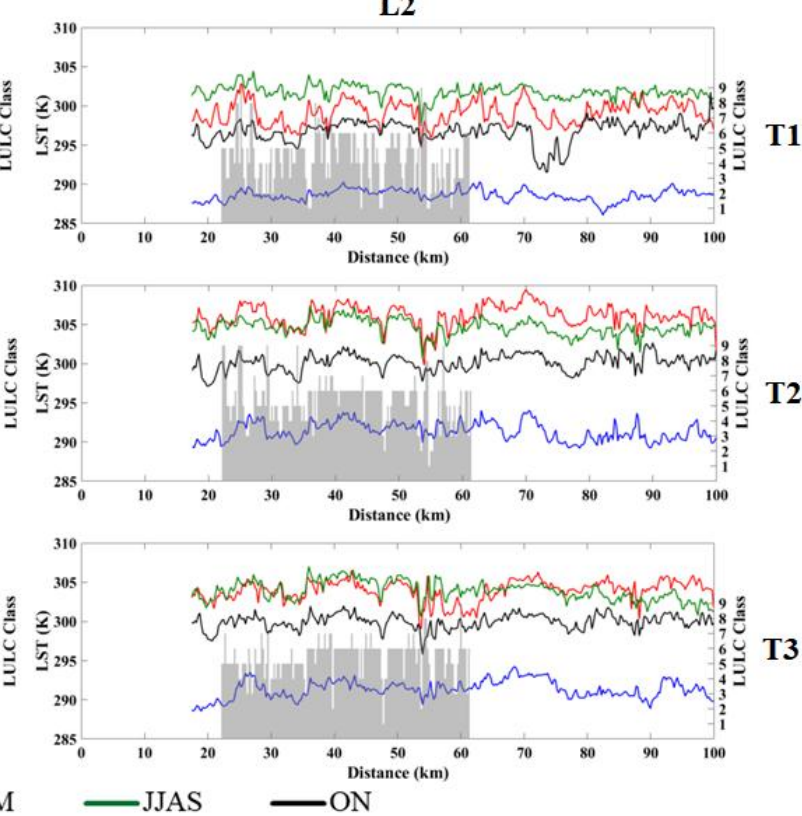

Figure 3. Spatial profile of LST (left y-axis) derived from Landsat dataset (30 $\mathrm{m}$ spatial resolution up-scaled to $250 \mathrm{~m}$ ), varying with nine (1-9) categories of LULC classes (right y-axis, grey bars) for NE-SW (L1) and NW-SE (L2) transects for various seasons during time periods 1991-1999 (T1), 2000-2008 (T2), and 2009-2016 (T3). Representation of LULC classes is as follows: 1-Dense Forest, 2-Open Forest, 3-Scrubs/ Degraded Forest, 4-Plantations, 5-Cultivable Area, 6-Built-up Area, 7-Road/ Rail Network, 8-River/ Waterbody, and 9-Wasteland.

$\mathbf{L 1}$
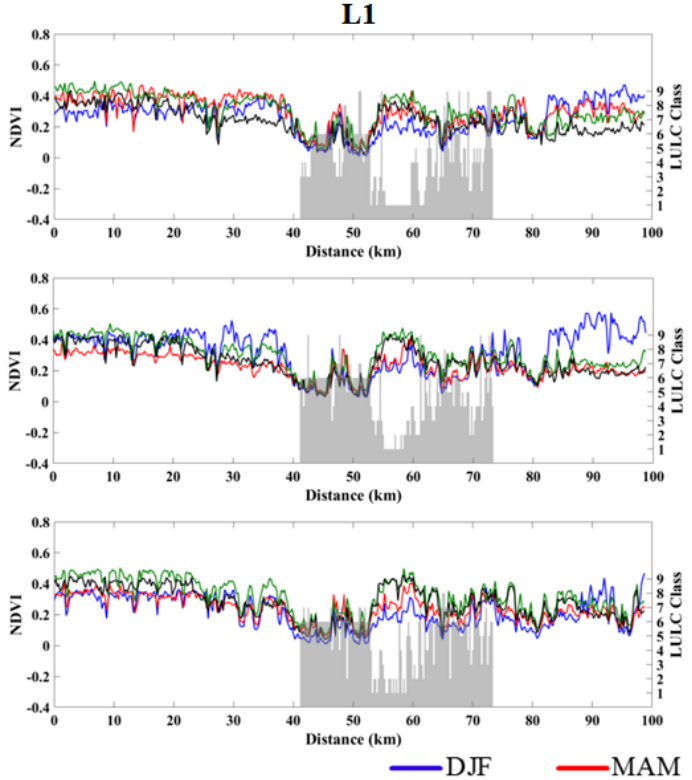

L2
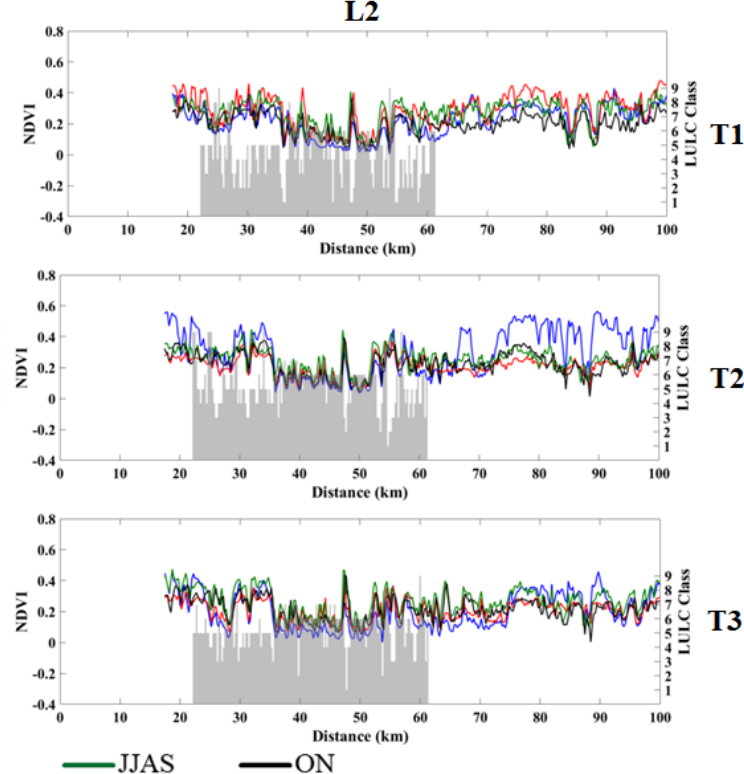

Figure 4. Same as Figure 3, but for NDVI. 
L1
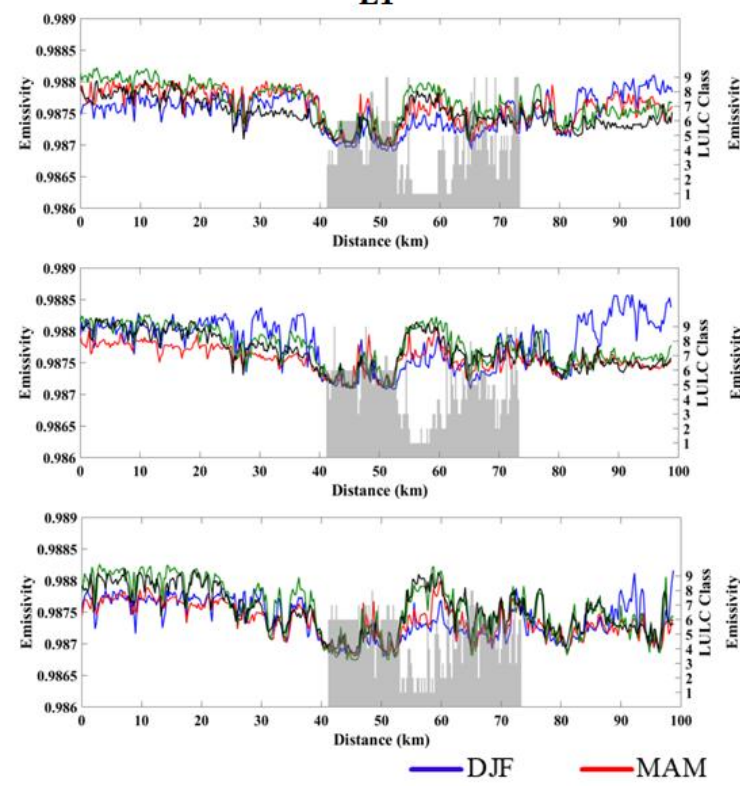

L2
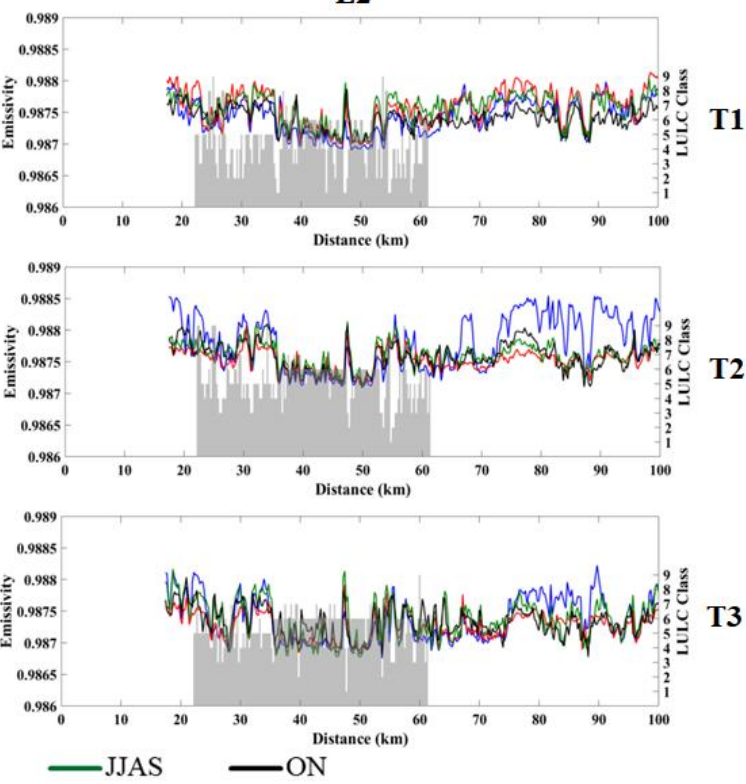

Figure 5. Same as Figure 3, but for emissivity.

Figure 4 shows the spatial profile of NDVI and over both transects. Emissivity variations for the same are illustrated in Figure 5. Consistently high NDVI values ranging from $0.3-0.5$ in the first $\sim 25 \mathrm{~km}$ of L1 transect suggests a dominant green cover. The green cover density is highest in JJAS, owing to the monsoon spells. Cropping practices i.e., sowing and harvesting seasons, as well as the availability of irrigation decide whether or not the land is left barren or is cultivated, thus influencing NDVI values. Frequent sharp dips in NDVI are noted in between 0-25 km distance; it represents the presence of small clusters of built-up regions, which are found in between a majorly cultivated area. High emissivity is found for regions with ample green cover and drastic fall is noted in the small built-up area clusters. Not much variation in LST is noted in the first $\sim 25 \mathrm{~km}$ in L1 transect along all of the periods, owing to a mostly unchanged LULC. As we approach the city border, a sharp decline in NDVI, as well as emissivity, is found because of the presence of barren soils and wasteland. Central ridge, a dense forest in the heart of Delhi $(\sim 53-63 \mathrm{~km})$, aids in lowering the temperature inside the city. Seasonal variation in NDVI for this stretch is due to the shedding season of leaves. In L2 transect, over time, land in the trans-Yamuna region of the city $(\sim 35-60 \mathrm{~km})$, has been mostly converted to dense built-up area. Same can be interpreted from Figures 4 and 5; a lower NDVI and emissivity values are found for this densely built-up region as compared to those with abundant green cover e.g., line transect L1 passing through the central ridge. Simultaneously, LST is found to be lower in the areas of forests and also along river Yamuna. Another evidence of local scale land-air interactions is a small patch of forest found at about $48 \mathrm{~km}$ in the $\mathrm{L} 2$ transect. While it is surrounded by built-up area on either side of the line transect, yet signatures of local modification in LST due to a different LULC class present, in between the densely built-up area, is captured. This patch shows remarkably high NDVI and emissivity, ultimately resulting in lowered LST than for its adjacent LULC classes. Seasonal variations in both of these variables is found to be fairly non-existent in built-up areas as its surface characteristics do not vary throughout the year, unlike the phenology seen in vegetation. Urban morphology and impervious surfaces in built-up areas combine to store heat, lower evaporative cooling, and increase surface sensible heat flux [17]. This high sensible heat flux leads to an increase in the LST, while presence of green cover as well as urban irrigation inside the urban areas has an opposite effect $[9,53]$. Overall for each individual type of surface i.e., LULC class across both transects, a distinct NDVI and emissivity value resulting in distinct signatures in LST is noted. Our analysis shows that LULC change, a local phenomenon is indeed an important temperature governing factor. 
Apart from NDVI and emissivity, we explore the interactions of other variables, such as albedo, evaporation, Bowen ratio, and PBL height on temperature (Figures S1-S4). However, the study is also limited due to $0.125^{\circ}$ spatial resolution dataset available from ERA-Interim suitable for only mesoscale variations. Nevertheless, in all of the plots, we find one distinct large scale pattern difference between L1 and L2 transect. As both these transects were chosen due to their differences in LULC, the patterns of ERA-Interim derived variables do indicate a possible role of local land surface changes on them. As was the case with Landsat derived variables, more spatial variation is noted for L1 transect from this dataset also. When compared to the NE side of L1 transect, the SW side has a higher albedo, Bowen ratio, and PBL height and a lower evaporation rate. Since the SW side is mainly the rocky terrain of the Aravalli range, it will have a higher albedo, reflective of the surface properties. Such surface as opposed to the cultivated regions in the NE side of L1 transect has higher surface sensible heat flux. Cultivated regions on the other hand have a higher surface latent heat flux due to evapotranspiration process. This explains the high Bowen ratio and low evaporation rate in the SW side. As surface sensible heat is higher on SW part of this transect, it leads to higher temperatures (as is evident from Figure 3), eventually resulting in an elevated PBL. From a seasonal perspective, LST is found to be higher in MAM and JJAS, albedo in ON and MAM, evaporation in JJAS, and Bowen ratio, as well as PBL height in MAM. In order to conclusively find associations between surface changes and all considered variables, correlation tests are employed and discussed in the next sub-section.

\subsection{Statistical Associations among Various Variables}

We finally assess the underlying associations existing between each of the variables. For this purpose, no bifurcation of data in terms of time periods and seasons for each studied variable is made. Mean and standard deviation $(1 \sigma)$ for both transects is tabulated for all of the variables (Table 1$)$. It is found that both LST and skin temperature is higher in L1 than in L2 transect. The corresponding, mean NDVI and emissivity is found to be comparatively higher in L1 than in the other transect. A lower evaporation rate alongside a higher Bowen ratio is able to justify high temperature in this transect. As temperature rises, the associated atmospheric energetics is more intense and also leads to an elevated PBL height. Negligible difference in albedo is noted. Furthermore, as observed in Figure 3, considerably higher variation of LST in L1 transect is also corroborated from Table 1. In general, the same is observed for all of the other variables. High standard deviation implies more heterogeneity in LULC in space, as well as time in L1.

Table 1. Mean and standard deviation of various variables in L1 (NE-SW) and L2 (NW-SE) transect. Number of samples for Landsat derived variables for L1 $=4572$ and for L2 $=3972$. For ERA-Interim derived variables the number of samples is 108 for both transects.

\begin{tabular}{ccccc}
\hline \multirow{2}{*}{ Variable } & \multicolumn{2}{c}{ L1 } & \multicolumn{2}{c}{ L2 } \\
\cline { 2 - 5 } & Mean & Std. Deviation & Mean & Std. Deviation \\
\hline LST (K) & 298.99 & 6.00 & 298.98 & 5.69 \\
NDVI & 0.27 & 0.110 & 0.24 & 0.100 \\
Emissivity & 0.988 & 0.00034 & 0.988 & 0.00031 \\
Skin Temperature (K) & 299.46 & 6.77 & 299.33 & 6.79 \\
Albedo & 0.18 & 0.007 & 0.1800 & 0.005 \\
Evaporation (mm/day) & 6.04 & 1.965 & 6.1 & 1.960 \\
Bowen Ratio & 0.37 & 0.12 & 0.34 & 0.11 \\
PBL Height (m) & 1002.96 & 857.24 & 996.24 & 846.92 \\
\hline
\end{tabular}

Results of parametric and non-parametric correlation tests applied for L1 transect are presented in Tables 2 and 3, and for L2 transect in Tables 4 and 5. Parametric correlation tests e.g., Pearson's r assumes an inherent linear relationship in the dataset while non-parametric correlation tests e.g., Spearman's $\varrho$ and Kendall's $\tau$ do not assume any such linearity in the considered variables. 
Associations for Landsat and ERA-Interim derived variables have been calculated separately due to differences in the number of samples.

Table 2. Parametric (Pearson's r) and non-parametric (Spearman's $\varrho$ and Kendall's $\tau$ ) correlation for Landsat derived variables in L1 transect. Number of samples $=4572$.

\begin{tabular}{ccccc}
\hline Correlation & Variable & LST & NDVI & Emissivity \\
\hline \multirow{3}{*}{ Pearson's correlation coefficient $(\mathrm{r})$} & LST & 1.000 & & \\
& NDVI & $-0.127^{* *}$ & 1.000 & \\
& Emissivity & $-0.137^{* *}$ & $0.880^{* *}$ & 1.000 \\
\hline \multirow{2}{*}{ Spearman rank correlation $(\varrho)$} & LST & 1.000 & & \\
& NDVI & $-0.182^{* *}$ & 1.000 & \multirow{2}{*}{ Emissivity } \\
& LST & $1.0000^{* *}$ & $0.881^{* *}$ & 1.000 \\
\hline \multirow{2}{*}{ Kendall rank correlation $(\tau)$} & NDVI & $-0.125^{* *}$ & 1.000 & \\
& Emissivity & $-0.118^{* *}$ & $0.702^{* *}$ & 1.000 \\
\hline
\end{tabular}

${ }^{* *}$ Correlation is significant at the 0.01 level (2-tailed).

Table 3. Parametric (Pearson's r) and non-parametric (Spearman's $\varrho$ and Kendall's $\tau$ ) correlation for ERA-Interim derived variables in L1 transect. Number of samples $=108$.

\begin{tabular}{|c|c|c|c|c|c|c|}
\hline Correlation & Variable & Skin Temperature & Albedo & Evaporation & Bowen Ratio & PBL Height \\
\hline \multirow{5}{*}{$\begin{array}{l}\text { Pearson's } \\
\text { correlation } \\
\text { coefficient }(\mathrm{r})\end{array}$} & Skin Temperature & 1.000 & & & & \\
\hline & Albedo & -0.005 & 1.000 & & & \\
\hline & Evaporation & $0.872^{* *}$ & $-0.196^{*}$ & 1.000 & & \\
\hline & Bowen Ratio & 0.117 & $0.274^{* *}$ & $-0.373^{* *}$ & 1.000 & \\
\hline & PBL Height & $0.815^{* *}$ & -0.022 & $0.467^{* *}$ & $0.616^{* *}$ & 1.000 \\
\hline \multirow{5}{*}{$\begin{array}{l}\text { Spearman rank } \\
\text { correlation }(\varrho)\end{array}$} & Skin Temperature & 1.000 & & & & \\
\hline & Albedo & $0.233^{*}$ & 1.000 & & & \\
\hline & Evaporation & 0.724 ** & -0.183 & 1.000 & & \\
\hline & Bowen Ratio & $0.210^{*}$ & $0.282^{* *}$ & $-0.448^{* *}$ & 1.000 & \\
\hline & PBL Height & $0.786^{* *}$ & -0.116 & $0.523^{* *}$ & $0.393^{* *}$ & 1.000 \\
\hline \multirow{5}{*}{$\begin{array}{l}\text { Kendall rank } \\
\text { correlation }(\tau)\end{array}$} & Skin Temperature & 1.000 & & & & \\
\hline & $\begin{array}{l}\text { Albedo } \\
\text { Albo }\end{array}$ & $0.192^{* *}$ & 1.000 & & & \\
\hline & Evaporation & $0.417^{\text {** }}$ & $-0.175^{* *}$ & 1.000 & & \\
\hline & Bowen Ratio & 0.094 & $0.234^{* *}$ & $-0.426^{* *}$ & 1.000 & \\
\hline & PBL Height & $0.616^{* *}$ & -0.031 & 0.124 & $0.352^{* *}$ & 1.000 \\
\hline
\end{tabular}

${ }^{* *}$ Correlation is significant at the 0.01 level (2-tailed). ${ }^{*}$ Correlation is significant at the 0.05 level (2-tailed).

Table 4. Parametric (Pearson's r) and non-parametric (Spearman's $\varrho$ and Kendall's $\tau$ ) correlation for Landsat derived variables in L2 transect. Number of samples $=3972$.

\begin{tabular}{ccccc}
\hline Correlation & Variable & LST & NDVI & Emissivity \\
\hline \multirow{2}{*}{ Pearson's correlation coefficient $(\mathrm{r})$} & LST & 1.000 & & \\
& NDVI & $-0.093^{* *}$ & 1.000 & \\
& Emissivity & $-0.136^{* *}$ & $0.869^{* *}$ & 1.000 \\
\hline \multirow{2}{*}{ Spearman rank correlation $(\varrho)$} & LST & 1.000 & & \\
& NDVI & $-0.091^{* *}$ & 1.000 & \\
& Emissivity & $-0.102^{* *}$ & $0.856^{* *}$ & 1.000 \\
\hline \multirow{2}{*}{ Kendall rank correlation $(\tau)$} & LST & 1.000 & & \\
& NDVI & $-0.066^{* *}$ & 1.000 & \\
& Emissivity & $-0.069^{* *}$ & $0.669^{* *}$ & 1.000 \\
\hline
\end{tabular}

\footnotetext{
${ }^{* *}$ Correlation is significant at the 0.01 level (2-tailed).
} 
Table 5. Parametric (Pearson's r) and non-parametric (Spearman's $\varrho$ and Kendall's $\tau$ ) correlation for ERA-Interim derived variables in L2 transect. Number of samples $=108$.

\begin{tabular}{|c|c|c|c|c|c|c|}
\hline Correlation & Variable & Skin Temperature & Albedo & Evaporation & Bowen Ratio & PBL Height \\
\hline \multirow{5}{*}{$\begin{array}{l}\text { Pearson's } \\
\text { correlation } \\
\text { coefficient }(\mathrm{r})\end{array}$} & Skin Temperature & 1.000 & & & & \\
\hline & Albedo & -0.037 & 1.000 & & & \\
\hline & Evaporation & $0.880^{* *}$ & -0.166 & 1.000 & & \\
\hline & Bowen Ratio & 0.152 & 0.109 & $-0.325^{* *}$ & 1.000 & $0.668^{* *}$ \\
\hline & PBL Height & $0.815^{* *}$ & -0.099 & $0.472^{* *}$ & $0.668^{* *}$ & 1.000 \\
\hline \multirow{5}{*}{$\begin{array}{l}\text { Spearman rank } \\
\text { correlation }(\varrho)\end{array}$} & Skin Temperature & 1.000 & & & & \\
\hline & Albedo & 0.127 & 1.000 & & & \\
\hline & Evaporation & $0.747^{* *}$ & $-0.193^{*}$ & 1.000 & & \\
\hline & Bowen Ratio & 0.179 & $0.217^{*}$ & $-0.412^{* *}$ & 1.000 & \\
\hline & PBL Height & $0.775^{* *}$ & $-0.306^{* *}$ & $0.539^{* *}$ & $0.413^{* *}$ & 1.000 \\
\hline \multirow{5}{*}{$\begin{array}{l}\text { Kendall rank } \\
\text { correlation }(\tau)\end{array}$} & Skin Temperature & 1.000 & & & & \\
\hline & $\begin{array}{l}\text { Albedo }\end{array}$ & 0.070 & 1.000 & & & \\
\hline & Evaporation & $0.491^{* *}$ & $-0.221^{* *}$ & 1.000 & & \\
\hline & Bowen Ratio & 0.047 & $0.132^{*}$ & $-0.364^{* *}$ & 1.000 & \\
\hline & PBL Height & $0.597^{* *}$ & $-0.170^{* *}$ & $0.171^{* *}$ & $0.383^{* *}$ & 1.000 \\
\hline
\end{tabular}

For both L1 and L2 transects, the correlations reveal a significant (at 99\% level of confidence) negative relationship between LST and NDVI (Tables 2 and 4). Emissivity varies gradually for most land cover features, as seen from Figure 5. Yet the study is able to capture the significant (at 99\% level of confidence) and dominant negative correlation with LST (as also expected by Stefan- Boltzmann relation). Similarly, a strong positive relationship exists between NDVI and emissivity. As NDVI is an indirect indicator for LULC classes, it can be said that LULC does significantly aid in altering LST. Indeed, LST is not solely dependent on emissivity. Other conditions, including climatic factors, such as evaporation, PBL height, etc., also play an important role in altering LST. The same is observed from Tables 3 and 5. Among the five ERA-interim variables, significant strong positive relationships exist between skin temperature and evaporation, skin temperature and PBL height and PBL height and evaporation for the two transects. A significant negative relationship exists between Bowen ratio and evaporation. Albedo has a weak significant relationship with Bowen ratio (positive association) and evaporation (negative association). Thus, both parametric and non-parametric correlation tests are able to explain interactions within various land-air variables.

\section{Conclusions}

This assessment provides significant confidence in the ability to study the urban transects and the mesoscale/regional land-atmosphere interactions that are influenced by urbanization using a combination of remote sensing/ satellite based land state and reanalysis products. The study is able to surmise that LULC change, a local scale phenomenon, indeed has a significant impact on regional features most directly through changes in the LST. Land surface variables e.g., NDVI, emissivity, albedo, and Bowen ratio, interact with the overlying atmosphere through various feedback systems and produce changes in LST, evaporation rates, as well as PBL height. The study looked at these variables because LST relates to the surface characteristics, evaporation (and latent heat flux) is linked to the land atmosphere processes coupled to the surface and PBL height is the ultimate indicator of the energetics of the boundary layer, as influenced by the surface. Indeed, future studies can build off these and look into factors such as cloudiness, circulation patterns, and vertical profiles at different transects. As mentioned, this study has provided the confidence to now under take such follow up assessments. Modifications forced by land surface changes have the ability to change atmospheric conditions of stability. High local scale spatio-temporal variations in LULC classes are noted in both of the considered transects. These spatio-temporal surface changes, manifest themselves as variations in patterns of LST. High NDVI and emissivity is observed in regions with abundant green cover and a 
drastic lowering is noted in built-up area clusters. Small changes in emissivity are linked with high variations in LST and ultimately in air temperature. For the Delhi city, as compared to the NE side (mainly cultivable areas) of L1 transect, the SW side (mainly the rocky terrain of the Aravalli range) has a lower evaporation rate. Low evaporation alongside a higher Bowen ratio and albedo explains high LST in the SW part of L1 transect. As temperature rises, it also leads to an elevated PBL height. From a seasonal aspect, generally across both transects, LST is found to be higher in MAM and JJAS i.e., summer months, albedo in ON and MAM, evaporation in JJAS, and Bowen ratio, as well as PBL height in MAM.

Parametric and non-parametric correlations reveal a significant negative relationship between LST and NDVI, as well as emissivity. As NDVI is an indirect indicator for LULC classes, it can be statistically said that LULC does significantly aid in altering LST. However LST is not solely dependent on emissivity or on NDVI. Other conditions, including climatic factors such as evaporation, PBL height, etc., also play an important role in altering LST. Significant strong positive relationships exist between skin temperature and evaporation, skin temperature, and PBL height and PBL height and evaporation. A significant negative relationship exists between Bowen ratio and evaporation. These associations are able to statistically establish the land-air interactions in the city. In order to further establish the modifications transpiring in the atmospheric system due to land surface changes, the alterations in occurrence, frequency and magnitude of extreme weather events in Delhi will be studied as a part of future investigations.

Supplementary Materials: Figure S1: Spatial profile of albedo calculated from ERA-Interim dataset $\left(0.125^{\circ}\right.$ spatial resolution), varying with LULC classes for NE-SW (L1) and NW-SE (L2) transect for various seasons during time periods: 1991-1999 (T1), 2000-2008 (T2), and 2009-2016 (T3). Representation of LULC classes is as follows: 1-Dense Forest, 2-Open Forest, 3-Scrubs/ Degraded Forest, 4-Plantations, 5-Cultivable Area, 6-Built-up Area, 7-Road/ Rail Network, 8-River/ Waterbody, and 9-Wasteland, Figure S2: Same as Figure S1, but for evaporation (mm/day), Figure S3: Same as Figure S1, but for Bowen ratio, Figure S4: Same as Figure S1, but for PBL height $(\mathrm{m})$.

Acknowledgments: Madhavi Jain acknowledges support of Senior Research Fellowship granted by the Council of Scientific and Industrial Research (CSIR), India. Dev Niyogi acknowledges grant from the Government of India (Grant no./ Project no. MM/SERP/CNRS/2013/INT-10/002) to conduct this research under Monsoon Mission, also NSF CAREER AGS-0847472, NSF AGS-1522494, and USDA NIFA Hatch grant. A. P. Dimri acknowledges support from UPoE-II, JNU.

Author Contributions: Madhavi Jain designed and performed the experiments. A. P. DIMRI and Dev Niyogi assisted in result analysis. All authors contributed in writing of the paper.

Conflicts of Interest: The authors declare no conflict of interest.

\section{References}

1. Bechtel, B.; Alexander, P.J.; Böhner, J.; Ching, J.; Conrad, O.; Feddema, J.; Mills, G.; See, L.; Stewart, I. Mapping local climate zones for a worldwide database of the form and function of cities. ISPRS Int. Geo-Inf. 2015, 4, 199-219. [CrossRef]

2. United Nations. World Population Prospects 2017. Available online: http:/ / esa.un.org/wpp/Documentation/ publications.htm (accessed on 7 April 2015).

3. Weng, Q.; Yang, S. Managing the adverse thermal effects of urban development in a densely populated Chinese city. J. Environ. Manag. 2004, 70, 145-156. [CrossRef] [PubMed]

4. Stewart, I.D.; Oke, T.R. Local climate zones for urban temperature studies. Bull. Amer. Meteor. Soc. 2012, 93, 1879-1900. [CrossRef]

5. Rosenzweig, C.; Solecki, W.; Hammer, S.A.; Mehrotra, S. Cities lead the way in climate-change action. Nature 2010, 467, 909-911. [CrossRef] [PubMed]

6. Stone, B.; Hess, J.J.; Frumkin, H. Urban form and extreme heat events: Are sprawling cities more vulnerable to climate change than compact cities. Environ. Health Persp. 2010, 118, 1425-1428. [CrossRef] [PubMed]

7. Ge, Y.; Dou, W.; Liu, N. Planning resilient and sustainable cities: Identifying and targeting social vulnerability to climate change. Sustainability 2017, 9, 1394. [CrossRef]

8. Oke, T.R. The energetic basis of the urban heat island. Q. J. R. Meteorol. Soc. 1982, 108, 1-24. [CrossRef] 
9. Arnfield, A.J. Two decades of urban climate research: A review of turbulence, exchanges of energy and water, and the urban heat island. Int. J. Climatol. 2003, 23, 1-26. [CrossRef]

10. Martilli, A. Numerical study of urban impact on boundary layer structure: Sensitivity to wind speed, urban morphology, and rural soil moisture. J. Appl. Meteorol. 2002, 41, 1247-1266. [CrossRef]

11. Karl, T.R.; Trenberth, K.E. Modern global climate change. Science 2003, 302, 1719-1723. [CrossRef] [PubMed]

12. Mitra, C.; Shepherd, J.M.; Jordan, T. On the relationship between the premonsoonal rainfall climatology and urban land cover dynamics in Kolkata city, India. Int. J. Climatol. 2012, 32, 1443-1454. [CrossRef]

13. Shepherd, J.M. A review of current investigations of urban-induced rainfall and recommendations for the future. Earth Interact. 2005, 9, 1-27. [CrossRef]

14. Dickinson, R.E. Land-atmosphere interaction. Rev. Geophys. 1995, 33, 917-922. [CrossRef]

15. Guide to meteorological instruments and methods of observation (WMO-No. 8). Available online: Https:/ /library.wmo.int/pmb_ged/wmo_8_en-2012.pdf (accessed on 30 May 2017).

16. Pielke, R.A.; Pitman, A.; Niyogi, D.; Mahmood, R.; McAlpine, C.; Hossain, F.; Goldewijk, K.K.; Nair, U.; Betts, R.; Fall, S.; et al. Land use/land cover changes and climate: Modeling analysis and observational evidence. Wiley Interdiscip. Rev.: Clim. Chang. 2011, 2, 828-850. [CrossRef]

17. Foley, J.A.; DeFries, R.; Asner, G.P.; Barford, C.; Bonan, G.; Carpenter, S.R.; Chapin, F.S.; Coe, M.T.; Daily, G.C.; Gibbs, H.K.; et al. Global consequences of land use. Science 2005, 309, 570-574. [CrossRef] [PubMed]

18. Grimmond, C.S.B.; Oke, T.R. Aerodynamic properties of urban areas derived from analysis of surface form. J. Appl. Meteorol. 1999, 38, 1262-1292. [CrossRef]

19. Xian, G.; Crane, M. An analysis of urban thermal characteristics and associated land cover in Tampa Bay and Las Vegas using Landsat satellite data. Remote Sens. Environ. 2006, 104, 147-156. [CrossRef]

20. Chen, X.L.; Zhao, H.M.; Li, P.X.; Yin, Z.Y. Remote sensing image-based analysis of the relationship between urban heat island and land use/cover changes. Remote Sens. Environ. 2006, 104, 133-146. [CrossRef]

21. Stathopoulou, M.; Cartalis, C. Downscaling AVHRR land surface temperatures for improved surface urban heat island intensity estimation. Remote Sens. Environ. 2009, 113, 2592-2605. [CrossRef]

22. Bowler, D.E.; Buyung-Ali, L.; Knight, T.M.; Pullin, A.S. Urban greening to cool towns and cities: A systematic review of the empirical evidence. Landsc. Urban Plan. 2010, 97, 147-155. [CrossRef]

23. Hua, W.; Chen, H.; Zhou, L.; Xie, Z.; Qin, M.; Li, X.; Ma, H.; Huang, Q.; Sun, S. Observational quantification of climatic and human influences on vegetation greening in China. Remote Sens. 2017, 9, 425. [CrossRef]

24. Bowen, I.S. The ratio of heat losses by conduction and by evaporation from any water surface. Phys. Rev. 1926, 27, 779-787. [CrossRef]

25. Betts, A.K.; Ball, J.H.; Beljaars, A.; Miller, M.J.; Viterbo, P.A. The land surface-atmosphere interaction: A review based on observational and global modeling perspectives. J. Geophys. Res. Atmos. 1996, 101, 7209-7225. [CrossRef]

26. Nicholson, S. Land surface processes and Sahel climate. Rev. Geophys. 2000, 38, 117-139. [CrossRef]

27. Wu, H.; Ye, L.P.; Shi, W.Z.; Clarke, K.C. Assessing the effects of land use spatial structure on urban heat islands using HJ-1B remote sensing imagery in Wuhan, China. Int. J. Appl. Earth Obs. 2014, 32, 67-78. [CrossRef]

28. Shashua-Bar, L.; Hoffman, M.E. Vegetation as a climatic component in the design of an urban street: An empirical model for predicting the cooling effect of urban green areas with trees. Energ. Build. 2000, 31, 221-235. [CrossRef]

29. Imhoff, M.L.; Zhang, P.; Wolfe, R.E.; Bounoua, L. Remote sensing of the urban heat island effect across biomes in the continental USA. Remote Sens. Environ. 2010, 114, 504-517. [CrossRef]

30. Li, X.; Li, W.; Middel, A.; Harlan, S.L.; Brazel, A.J.; Turner, B.L. Remote sensing of the surface urban heat island and land architecture in Phoenix, Arizona: Combined effects of land composition and configuration and cadastral-demographic-economic factors. Remote Sens. Environ. 2016, 174, 233-243. [CrossRef]

31. Zhou, L.; Dickinson, R.E.; Tian, Y.; Fang, J.; Li, Q.; Kaufmann, R.K.; Tucker, C.J.; Myneni, R.B. Evidence for a significant urbanization effect on climate in China. Proc. Natl. Acad. Sci. USA 2004, 101, 9540-9544. [CrossRef] [PubMed]

32. Seneviratne, S.I.; Lüthi, D.; Litschi, M.; Schär, C. Land-atmosphere coupling and climate change in Europe. Nature 2006, 443, 205-209. [CrossRef] [PubMed]

33. Kishtawal, C.M.; Niyogi, D.; Tewari, M.; Pielke, R.A.; Shepherd, J.M. Urbanization signature in the observed heavy rainfall climatology over India. Int. J. Climatol. 2010, 30, 1908-1916. [CrossRef] 
34. Shastri, H.; Paul, S.; Ghosh, S.; Karmakar, S. Impacts of urbanization on Indian summer monsoon rainfall extremes. J. Geophys. Res. Atmos. 2015, 120, 496-516. [CrossRef]

35. McLeod, J.; Shepherd, M.; Konrad, C.E. Spatio-temporal rainfall patterns around Atlanta, Georgia and possible relationships to urban land cover. Urban Clim. 2017, 21, 27-42. [CrossRef]

36. Niyogi, D.; Pyle, P.; Lei, M.; Arya, S.P.; Kishtawal, C.M.; Shepherd, M.; Chen, F.; Wolfe, B. Urban modification of thunderstorms: An observational storm climatology and model case study for the Indianapolis urban region. J. Appl. Meteorol. Clim. 2011, 50, 1129-1144. [CrossRef]

37. Steiger, S.M.; Orville, R.E.; Huffines, G. Cloud-to-ground lightning characteristics over Houston, Texas: 1989-2000. J. Geophys. Res. Atmos. 2002, 107, 1-12. [CrossRef]

38. Stallins, J.A.; Bentley, M.L. Urban lightning climatology and GIS: An analytical framework from the case study of Atlanta, Georgia. Appl. Geogr. 2006, 26, 242-259. [CrossRef]

39. Jain, M.; Dawa, D.; Mehta, R.; Dimri, A.P.; Pandit, M.K. Monitoring land use change and its drivers in Delhi, India using multi-temporal satellite data. Model. Earth Syst. Environ. 2016, 2, 1-19.

40. Dee, D.P.; Uppala, S.M.; Simmons, A.J.; Berrisford, P.; Poli, P.; Kobayashi, S.; Andrae, U.; Balmaseda, M.A.; Balsamo, G.; Bauer, P.; et al. The ERA-Interim reanalysis: Configuration and performance of the data assimilation system. Q. J. R. Meteorol. Soc. 2011, 137, 553-597. [CrossRef]

41. Gao, L.; Schulz, K.; Bernhardt, M. Statistical downscaling of ERA-interim forecast precipitation data in complex terrain using lasso algorithm. Adv. Meteorol. 2014, 1-16. [CrossRef]

42. Zhou, C.; Wang, K. Evaluation of surface fluxes in ERA-Interim using flux tower data. J. Clim. 2016, 29, 1573-1582. [CrossRef]

43. Shastri, H.; Barik, B.; Ghosh, S.; Venkataraman, C.; Sadavarte, P. Flip flop of day-night and summer-winter surface urban heat island intensity in India. Sci. Rep. 2017, 7, 1-8. [CrossRef] [PubMed]

44. Jain, M.; Dimri, A.P. Efficacy of filtering techniques in improving landsat SLC-off thermal infra-red data. IEEE J. Sel. Topics Appl. Earth Observ. Remote Sens. 2017, 99, 1-14. [CrossRef]

45. NASA, Landsat 7 Science Data Users Handbook. Available online: https://landsat.gsfc.nasa.gov/wpcontent/uploads/2016/08/Landsat7_Handbook.pdf (accessed on 8 September 2016).

46. Sobrino, J.A.; Jiménez-Muñoz, J.C.; Paolini, L. Land surface temperature retrieval from LANDSAT TM 5. Remote Sens. Environ. 2004, 90, 434-440. [CrossRef]

47. Tran, H.; Uchihama, D.; Ochi, S.; Yasuoka, Y. Assessment with satellite data of the urban heat island effects in Asian mega cities. Int. J. Appl. Earth Obs. 2006, 8, 34-48. [CrossRef]

48. Jain, M.; Dimri, A.P.; Niyogi, D. Year-round daytime cold island in a highly urban city. Remote Sens. Environ. 2017. submitted.

49. Vancutsem, C.; Ceccato, P.; Dinku, T.; Connor, S.J. Evaluation of MODIS land surface temperature data to estimate air temperature in different ecosystems over Africa. Remote Sens. Environ. 2010, 114, 449-465. [CrossRef]

50. Carlson, T.N.; Ripley, D.A. On the relation between NDVI, fractional vegetation cover, and leaf area index. Remote Sens. Environ. 1997, 62, 241-252. [CrossRef]

51. Houghton, R.A. The worldwide extent of land-use change. BioScience 1994, 44, 305-313. [CrossRef]

52. Lunetta, R.S.; Knight, J.F.; Ediriwickrema, J.; Lyon, J.G.; Worthy, L.D. Land-cover change detection using multi-temporal MODIS NDVI data. Remote Sens. Environ. 2006, 105, 142-154. [CrossRef]

53. Theeuwes, N.E.; Steeneveld, G.J.; Ronda, R.J.; Rotach, M.W.; Holtslag, A.A. Cool city mornings by urban heat. Environ. Res. Lett. 2015, 10, 1-9. [CrossRef]

(C) 2017 by the authors. Licensee MDPI, Basel, Switzerland. This article is an open access article distributed under the terms and conditions of the Creative Commons Attribution (CC BY) license (http:/ / creativecommons.org/licenses/by/4.0/). 